\title{
INVESTIGATION WITH PANEL DATA ANALYSIS OF THE EFFECT ON ECONOMIC GROWTH OF EMPLOYMENT IN AGRICULTURE AND INDUSTRIAL SECTOR: EXAMPLE OF SOME OECD COUNTRIES (1993-2017)
}

DOI: 10.17261/Pressacademia.2019.1049

JEFA- V.6-ISS.2-2019(5)-p.102-114

Sakir Isleyen

Van Yüzüncü Yıl University, School of Economics and Administrative Sciences, Department of Econometrics, Van, Turkey. sakirisleyen@yyu.edu.tr, ORCID: 0000-0002-8186-1990

\begin{tabular}{l}
\hline Date Received: April 30, 2019 Date Accepted: June 25, 2019 \\
\hline To cite this document \\
Isleyen, S., (2019). Investigation with panel data analysis of the effect on economic growth of employment in agriculture and industrial \\
sector: example of some OECD countries (1993-2017). Journal of Economics, Finance and Accounting (JEFA), V.6(2), p.102-114. \\
Permemant link to this document: http://doi.org/10.17261/Pressacademia.2019. \\
Copyright: Published by PressAcademia and limited licenced re-use rights only.
\end{tabular}

\section{ABSTRACT}

Purpose- Economic growth is one of the biggest indicators of the strength of a country. Countries provide economic growth by generating resources with their advanced technology. In this study, for some OECD countries (Germany, Belgium, Canada and Turkey) was investigated effect on the economic growth of the employment in the agriculture and industrial sector using panel data analysis. In the study, annual data were used from the years 1993-2017.

Methodology- The data were taken from the official web address of the World Bank. Firstly, the data to be used in the model were examined by "unit root tests" to determine whether these series are stationary. According to the results of the unit root test applied to the levels of the variables, it was seen that the series were not stationary but contained unit root. For this reason, the primary differences of the series were taken and found to be stationary. Then the co-integration test was performed.

Findings- The results of the cointegration tests performed indicate that there is a cointegration and there is a long-term relationship between the variables. In the study, classical, fixed effect and random effective regression models were used. The Hausman test was applied to determine the correct regression to be used, resulting in the appropriate model being the random effect model.

Conclusion- After the Haussmann test, the most appropriate model was obtained as a random effect model.
\end{abstract}

Keywords: Economic growth, employment, panel data analysis, agriculture, industry.

JEL Codes: C00, C01, C23

\section{TARIM VE SANAYI SEKTÖRÜNDE ISTIHDAMIN EKONOMIK BÜYÜME ÜZERINDEKI ETKISI: BAZI OECD ÜLKELERI ÖRNEĞi (1993-2017)}

\section{ÖZET}

Amaç- İktisadi büyüme bir ülkenin gücünü gösteren en büyük göstergelerden biridir. Ülkeler ekonomik büyümeyi, sahip oldukları kaynakları çağın gelişmiş teknolojisiyle üretime geçirerek sağlarlar. Bu çalışmada, bazı OECD ülkeleri (Almanya, Belçika, Kanada ve Türkiye) için tarım ve sanayi sektöründe istihdamın ekonomik büyüme üzerindeki etkisi panel veri analizi kullanılarak incelendi. Çalışmada, $1993-2017$ yılları arası yıllık veriler kullanıldı.

Yöntem- Veriler Dünya Bankasının (Worldbank) resmi web adresinden alındı. İlk olarak, modelde kullanılacak olan verilerin "birim kök testleri" yapılarak bu serilerin durağan olup olmadığı incelendi. Değişkenlerin seviyelerine uygulanan birim kök test sonuçlarına göre, serilerin durağan olmadığı ancak birim kök içerdikleri görüldü.

Bulgular- Bu nedenle serilerin birincil farkları alınarak durağan olduğu belirlendi. Daha sonra eş-bütünleşme testi gerçekleştirildi. Yapılan eşbütünleşme testleri sonucu eş-bütünleşmenin var olduğu ve bu sonuç doğrultusunda değişkenler arasında uzun dönem ilişkinin varlığı tespit edildi. Çalışmada klasik, sabit etki ve rassal etkili regresyon modelleri kullanıldı

Sonuç- Kullanılacak doğru regresyonun tespiti için Hausman testi uygulanarak, uygun modelin rassal etkili model olduğu sonucuna varıldı.

Anahtar Kelimeler: Ekonomik büyüme, İstihdam, Panel veri analizi, Tarım, Endüstri.

JEL Kodları: C00, C01, C23 


\section{GiRiş}

Ekonomi politikasının en önemli amaçlarından biri, ekonomik büyümenin gerçekleşmesidir. Bu doğrultuda, üretim olanaklarının dışa doğru büyümesi şeklinde tanımlanan iktisadi büyümenin gerçekleştirilmesi toplum refah seviyesinin artması için önemli bir ön koşuldur. Günümüzde birçok ülkenin kapalı ekonomiden vazgeçtiği, yeni ve açık ekonomi anlayışları benimsediği görülmektedir. Bu anlayışı benimseyen ülkelerin dış ticaretin artış gösterdiği ve bu yolla istihdamın sağlandığı görülmektedir (Karaçor ve Saraç, 2011). Sanayi; kelime kökeni Arapça dilinden gelmekte olup hammaddeleri işlemek, enerji kaynaklarını yaratmak için kullanılan yöntemlerin ve araçların bütünü şeklinde tanımlanabilir. Yeni teknolojileri uygulamadaki tavırları ve yasal durumları ne olursa olsun büyük, küçük ve orta ölçekli işletmelerin gerçekleştirdikleri her türlü iktisadi etkinlik, sanayi olarak değerlendirilir. Gerek sektörel denge açısından ve gerekse uzun dönemde yatırım, istihdam ve katma değer yaratması bakımından sanayi sektörünün genel ekonomi içinde önemli yer tuttuğu açıktır. Ekonomide kalıcı istikrar için tarım, sanayi ve hizmet sektörleri arasında belirli bir denge olmalıdır (Korkmaz, E. 2016).

Gayrisafi yurt içi hasıla (GSYiH), bir ülkenin iktisadi büyüklüğünü gösteren önemli ölçütlerden biridir. GSYiH, Gayrisafi Milli Hasıla (GSMH)'dan farklı olarak, bir ülke sınırları içerisinde belli bir dönem içinde, üretilen tüm nihai mal ve hizmetlerin para birimi cinsinden karşıı̆ıdır. İktisadi büyüme ve sanayileşme arasındaki ilişki iktisadi anlamda önem arz eden bir çalışma alanıdır. Neoklasik iktisatçıların kabul gördüğü Kaldor anlayışı "sanayiyi büyümenin motoru olarak görmek" sanayi sektöründe sermayenin veya yatırımların önemli bir kazanç sağladığı önemini belirtmektedir. Sanayi sektöründe meydana gelen bir artış ekonomiyi olumlu yönde etkileyip büyümeyi hızlandırmaktadır. Kaldor'un yanısıra Verdoorn Kanunu, sanayi sektöründeki üretim artışının bu sektördeki verimliliği daha hızıı bir şekilde büyümesine neden olacağını savunmaktadır (Terzi ve Oltulular, 2004).

Ülkelerin sürekli bir gelişim içinde olması ve gelişmenin doğurduğu gerekliliklerden dolayı ekonominin baş sektörü olan tarım sektörü, zamanla değerini kaybederek gelişmiş ülkelerde gerileme göstermiştir. Bu süreç, gelişmekte olan ülkelerde de aynı şekilde devam etmektedir. Sektörün bu şekilde gerilemesinden kaynaklı olarak bu alanda olan istihdam da gün geçtikçe kan kaybetmektedir. Gelişmekte olan ülkelerde kırsal bölgelerde geçimini sağlayan insanlar halen bu sektörde direnme göstermektedirler. Ülkelerin kalkınmasında tarım önemli fonksiyonlara sahiptir. Bu fonksiyonlar; beslenme için şart olan gıda maddeleri üretiminin sağlanması, sanayi ürünlerine talebin artırılması, sanayi üretimi için ihtiyaç duyulan hammadde, sermaye ve emeğin sağlanması, ekonominin döviz gereksiniminin giderilmesi v.b. olarak sıralanabilir. Bu fonksiyonlardan kaynaklı olarak tarımın büyük önem taşıdığı açık bir şekilde görülmektedir (Doğan, 2009).

İstihdam kavramı, iki anlamda tanımlanmaktadır. Birincisi, geniş anlamda mal ve hizmet üretmek için üretim etkenlerinin üretim süresi boyunca kullanılmasını kapsar. İkincisi, dar anlamda sadece emek etkeninin mal ve hizmet üretmek için üretim sürecinde kullanılmasını içermektedir. Bundan dolayı bir ekonomide emek etkeninin istihdamı düşük ise, söz konusu ekonomide işsizlik sorunu meydana gelmektedir (Uysal, 2007: 55).

Türkiye'de 1980'lerin sonunda sanayinin GSYiH içindeki payı \%34 oranında iken, bugün \%27’ye gerilediği görülmektedir. Sanayi sektörünün GSYiH içindeki payının azalması ekonomide gerileme ve yoksullaşma anlamına gelmez. İlerleme gösteren ülkelerde hizmet sektörünün ekonomideki payı daha yüksektir. Fakat sanayide üretim endeksinin sürekli düşüş yaşaması ekonomik durgunluğa neden olabilir (Korkmaz, 2016). Ayrıca sanayi sektöründe var olan istihdamın artışı bu sektörün ilerleme gücünü gösteren önemli unsurlardan biridir. Aşağıda 1993-2017 yılları arası bazı OECD ülkelerine (Almanya, Belçika, Kanada ve Türkiye) ait ekonomik büyüme, tarım ve sanayi sektöründe olan istihdam verileri grafikler halinde verilmiştir.

Almanya, ekonomik büyüme gücü olarak dünya ülkeleri arasında üçüncü sırada, sanayi ve teknoloji üretimi sektöründe ise dünyanın ilk dört ülkesi içinde yer almaktadır. Sanayinin GSYiH içindeki payı \%30 oranındadır. Tarım alanında organik tarımı destekleyen teşvikler oluşturan Almanya tüketiminin büyük oranını kendi üretiminden karşılamaktadır. Tarımındaki GSYiH içindeki payı düşük olmasına rağmen, tarım alanında dışa bağımlıı̆̆ı düşük orandadır. Aşağıda yer alan grafikte 1993-2017 yılları arasında Almanya'ya ait ekonomik büyüme, tarım alanında istihdam ve sanayi alanında istihdamın yıllara göre oranları verilmiştir. 
Grafik 1: 1993-2017 Almanya GSYIH, iSTARIM ve iSSANAYi Verileri

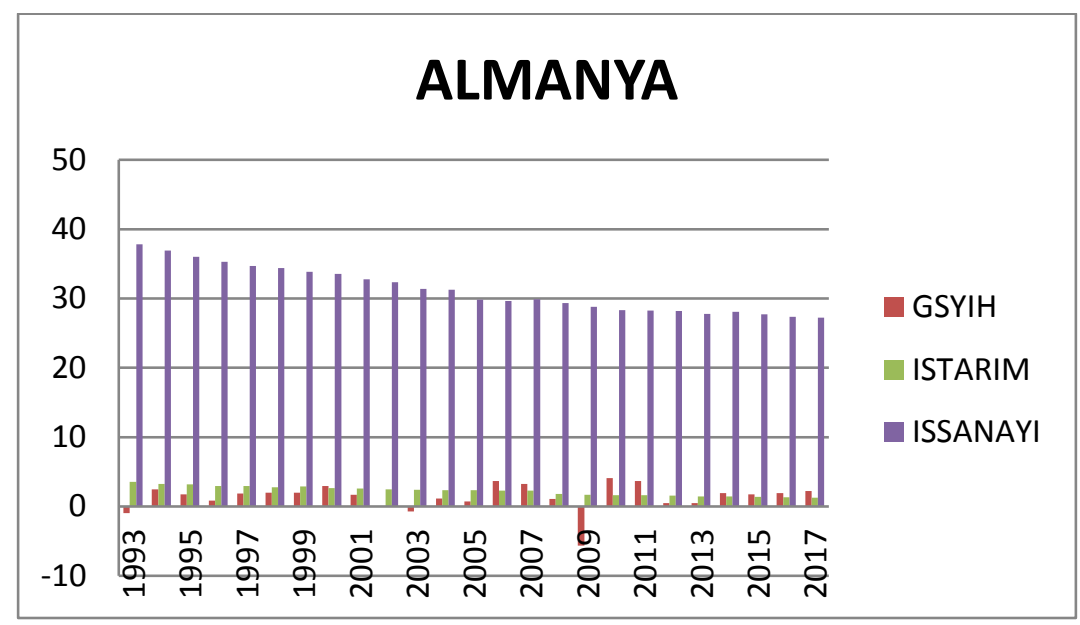

Grafik-1 incelendiğinde; Almanya'da istihdamın büyük oranla sanayi sektöründe olduğu görülmektedir. Tarım alanında istihdamın ise düşük oranda olduğu görülmektedir. Almanya iktisadi büyüme olarak dalgalı dönemler yaşamıştır. 1990 yılında meydana gelen ve yaklaşık 7 ay süren Körfez savaşından dolayı küresel savaşın etkileri devam etmiştir. Almanya'da 1993 yılında bu savaşın etkisi gayet net görülmektedir. Daha sonra 2008 ve 2009 yıllarında meydana gelen küresel krizden etkilenen tüm dünya ülkeleri gibi Almanya'da etkilenmiştir. Grafik-1'de Almanya için bu küresel etkinin sonucu açık bir şekilde görülmektedir.

Belçika, 19.yy'da endüstri devrimine katılan ilk kıta ülkesidir. Bulunduğu konum gereği Avrupa'nın birçok ülkesine sınırı bulunmaktadır. Bundan dolayı Avrupa'nın alt yapı ve ulaşım olarak gelişmiş ülkelerinden biridir. Belçika da hizmet sektörü olarak gelişmiş bir ülkedir. Teknolojik olarak gelişmiş bir ülke olan Belçika sanayi sektöründe de gelişmişlik göstermektedir. Topraklarının \%44'ü tarıma elverişli olmasına rağmen \%27.2'sini kullanmaktadır. Genellikle şeker pancarı, patates ve buğday üretimi ülkede yaygın durumdadır. Aşağıda yer alan grafikte 1993-2017 yılları arasında Belçika'ya ait ekonomik büyüme, tarım alanında istihdam ve sanayi alanında istihdamın yıllara göre oranları verilmiștir.

Grafik 2: 1993-2017 Belçika GSYiH, ISTARIM ve isSANAYi Verileri

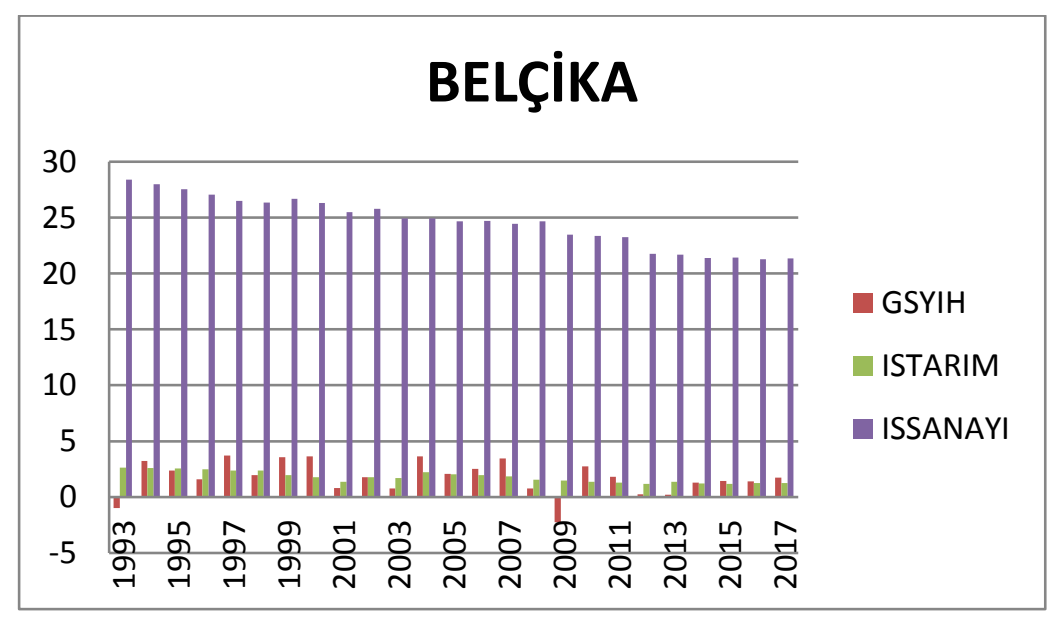

Grafik-2 incelendiğinde; Belçika'da istihdamın büyük oranla sanayi sektöründe olduğu ve tarım alanında istihdamın ise düşük oranda olduğu görülmektedir. Belçika için ekonomik büyüme diğer dünya ülkelerinde olduğu gibi dalgalı süreçler yaşamıştır. Özellikle 1990 yılında meydana gelen Körfez savaşından dolayı küresel savaşın etkileri burada da devam etmiştir. 1993 yılında bu savaşın etkisi gayet net görülmektedir. Daha sonra 2008 ve 2009 yıllarında meydana gelen küresel krizden etkilenen tüm dünya ülkeleri gibi Belçika'da etkilenmiştir. Grafik-2'de bu küresel etkinin sonucu açıktır.

OECD ve G8 ülkesi olan Kanada dünyanın gelişmiş ülkeleri arasında yer almaktadır. Büyük bir ekonomik güce sahip Kuzey Amerika ülkesi olan Kanada da karma ekonomik modelini kullanmaktadır. Maden ve hizmet sektöründe ilerleme gösteren bir ülkedir. Ormancılık ve ham petrol sektöründe büyük bir güce sahip olan ülke, sert ikliminden kaynaklı tarım alanının çok az 
kısmını kullanmaktadır. Tarım alanının \%7'sinin kullanabilen Kanada buna rağmen buğday ihracatı yapan bir ülkedir. Aşağıda yer alan grafikte 1993-2017 yılları arasında Kanada'ya ait ekonomik büyüme, tarım alanında istihdam ve sanayi alanında istihdamın yıllara göre oranları verilmiştir.

\section{Grafik 3: 1993-2017 Belçika GSYIH, ISTARIM ve iSSANAYi Verileri}

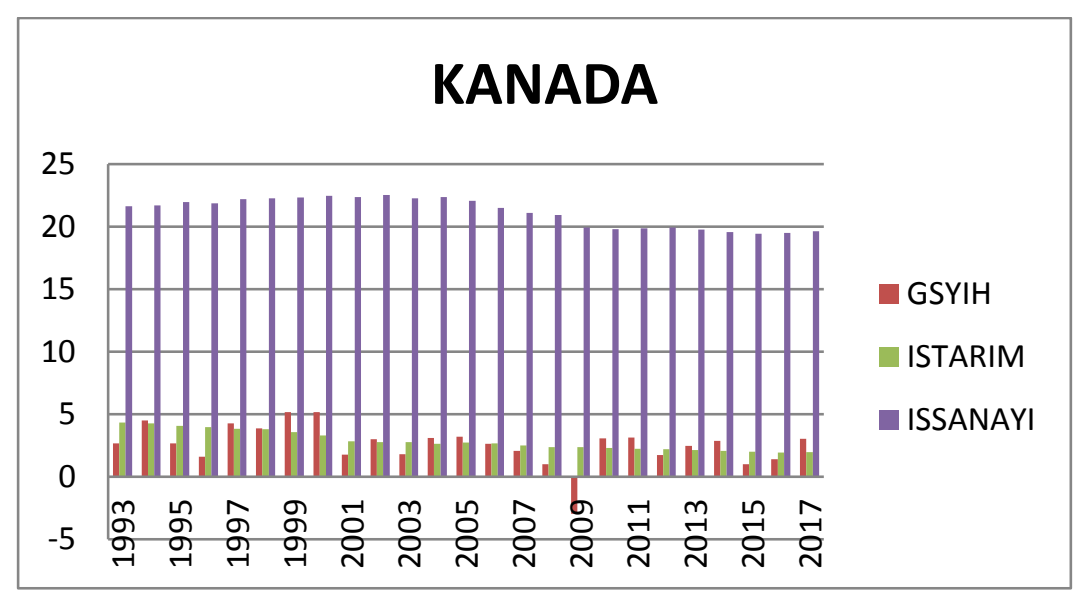

Grafik-3 incelendiğinde; Kanada'da istihdamın büyük oranla sanayi sektöründe olduğu ve tarım alanında istihdamın ise düşük oranda olduğu görülmektedir. Kanada da genel olarak ekonomik büyümede dalgalı süreçlerle büyüme yaşayan ülkelerdendir. Kanada, 1993 krizinden diğer OECD ülkeleri içinde en az etkilenen ülkelerden biridir. Daha sonra 2008 ve 2009 yıllarında meydana gelen küresel krizden etkilenen tüm dünya ülkeleri gibi Kanada'da etkilenmiştir. Grafik-3'te bu küresel etkinin sonucu gayet net bir şekilde görülmektedir.

Türkiye gelişmekte olan ülkeler arasında yer alan bir ülkedir. Tarım alanlarının \%36'sını kullanan Türkiye, son zamanlarda tarım alanında ithal ürünler kullanmaya başlamıştır. Bundan dolayı üretim oranlarında düşüşler yaşamaktadır. Çeşitli iklim türlerinin olmasından kaynaklı birçok ürününün yetiştiği bir ülke olan Türkiye, bu anlamda bir tarım ülkesi olarak adlandırılmaktadır. Gelişmekte olan bir ülke konumundaki Türkiye, son zamanlarda gelişmiş olan ülkeler statüsüne çıkmak için sanayi sektöründe ilerleme göstermektedir. Aşağıda yer alan grafikte 1993-2017 yılları arasında Türkiye'ye ait ekonomik büyüme, tarım alanında istihdam ve sanayi alanında istihdamın yıllara göre oranları verilmiştir.

Grafik 4: 1993-2017 Türkiye GSYiH, ISTARIM ve isSANAYi Verileri

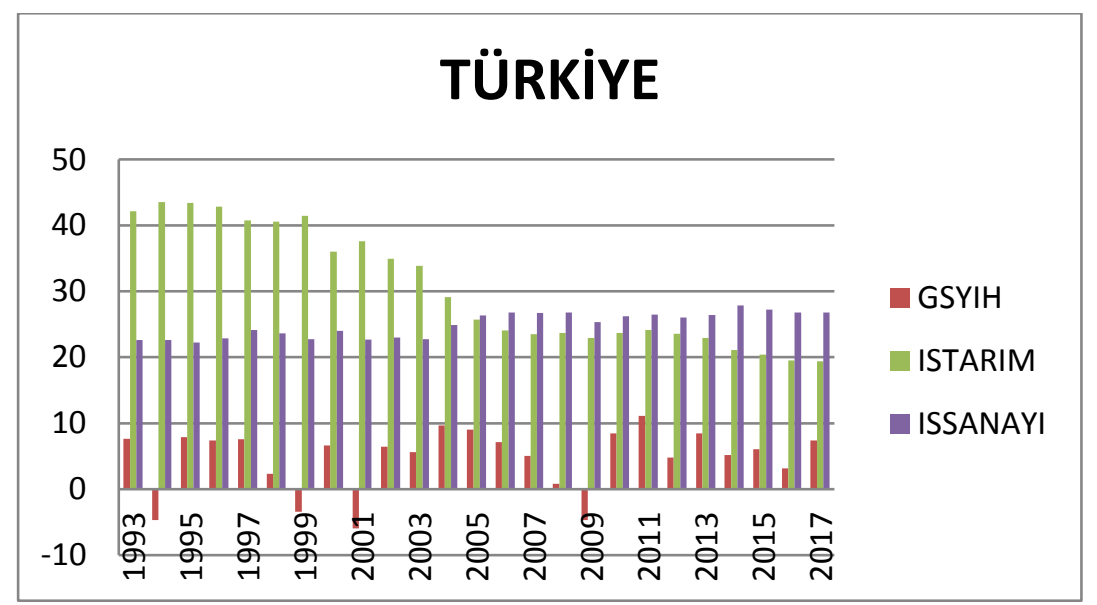

Grafik-4 incelendiğinde; Türkiye'de son zamanlarda istihdamın sanayi sektörüne yöneldiği ve tarım alanında istihdamın ise, gittikçe düşüşe geçtiği görülmektedir. Türkiye iktisadi büyümede dalgalanmaların en çok olduğu ülkelerden biridir. Aynı Kanada gibi, Türkiye de 1993 krizinden en az etkilenen ülkelerden biri olmasına rağmen sonraki yaşanan süreçlerde ekonomik büyüme olarak olumsuzluklar yaşadığı Grafik-4'te net bir şekilde görülmektedir. Özellikle 1994, 1999, 2001 ve 2009 yıllarında yaşanan gerek iç gerek dış krizlerden olumsuz etkilenen OECD ülkelerinden biri de Türkiye'dir. Bu krizin olumsuz etkileri Grafik4 dikkate alındı̆̆ında net bir şekilde görülmektedir. 


\section{KAVRAMSAL ÇERÇEVE VE LITERATÜR}

Literatür incelendiğinde genel olarak ekonomik büyüme ile tarım ve sanayi sektöründe üretim arasındaki ilişki analizi yapıldığı görülmektedir. Bunun yanısıra istihdam genel olarak ele alınmış ve iktisadi büyüme ile bu bağlamda ilişki analizi yapılmıştır. Yapılan çoğu araştırma sonucu ekonomik büyüme ile tarım ve sanayi sektöründe üretim arasında pozitif yönlü bir ilişkinin olduğu görülmüştür. Aynı biçimde istihdam ve ekonomik büyüme arsasında da pozitif bir ilişkinin mevcut olduğu literatürde yer almıştır.

Ekonomik büyüme; refah seviyesinin toplum olarak artması, yaşam standartlarının iyileşmesi olarak tanımlanmaktadır. Literatürde, ekonomik büyüme; GSMH'da ortaya çıkan sürekli artıştan kişi başına düşen milli gelirin artması olarak açıklanmaktadır. Ekonomik büyümenin ölçülmesinde; kişi başına düşen milli gelirde uzun bir dönemde gerçekleşen yıllık değişimi ifade eden "ortalama büyüme hızı" kavramı kullanılmaktadır (Ünsal, 2007: 11). Joseph Schumpeter tarafından yapılan ve literatürde yaygın bir biçimde kullanılan söz konusu tanıma göre; Ekonomik büyüme kısa dönemli statik olarak değil, tam tersi uzun dönemli dinamik bir olgudur tanımı yapılmaktadır (Taban, 2008: 1).

İstihdamı iki temel faktör belirler. Bunlar yurtiçi mal ve hizmet talebidir. Ayrıca ithalat ve ihracat, istihdamı etkileyen diğer faktörlerdendir. Ekonomik büyümenin var olduğu ülkelerde istihdamın da yüksek olduğu görülmektedir. İstihdamı etkileyen diğer faktörler; teknoloji, iş gücü maliyeti ve kapasite kullanımı şeklinde sıralanabilir (Akyıldız, 2006:63). GSMH, var olan istihdam oranına ve istihdama katılan işgücünün verimliliğine bağlı gelişim göstermektedir. Öte yandan istihdamda yer alan beşeri sermayeden kaynaklı ekonomik büyüme, istihdamdan etkilenmektedir. İstihdamın insanda meydana getirdiği yetenek ve bilgiden kaynaklı artan beşeri sermaye iktisadi büyümeyi pozitif yönde etkilemektedir (Parasız, 2008:11). Bazı görüşler, istihdamın iktisadi büyümeyi kısa dönemde daha çok etkilediğini, uzun dönemde ise teknolojik ilerleme ile bunun meydana geldiğini belirtmektedir (Ülgener, 1991:50). İstihdamın ekonomik büyüme üzerindeki etkisi analiz edilirken, iktisadi büyümenin iç pazara mı yoksa dış pazara mı yönlendiği, büyümede emeğin mi yoksa sermayenin mi daha yoğun olduğu, iktisadi büyümenin sektördeki hızının ne olduğu büyük önem arz etmektedir (Yılmaz Göktaş, 2005:64).

İnsanoğlunun var oluşundan günümüze tarımsal üretim önemli bir yer tutmuştur. Hayatın sürdürülmesi zorunlu olan gıda intiyacımızı içeren tarımsal üretim son derece önemlidir. İnsanoğluna sağladığı bu faydalardan dolayı tarımsal üretim aynı zamanda ekonomik kalkınmayı da bu şekilde sağlamaktadır (Boz, 2004:139). Yaşamın devamını sağlamak için beslenme en önemli şarttır. Beslenmeyi sağlayan gıda ürünleri üreten tarım sektörü bundan dolayı büyük önem taşır. Bu kadar önemli bir konuma sahip olan tarım üretiminin oluşabilmesi için önemli kaynaklar sağlanmalı ve destekleme politikaları izlenmelidir. Globalleşen dünyada, gelişmiş ve gelişmekte olan ülkeler tarım üretiminde dışa bağımlılığı düşürüp kendi üretimleri ile intiyaçlarını karşılamak istemektedirler. Bunda dolayı birçok ülke bu konuda destekleme programları yapıp gıda alanında güvenliğini sağlamak istemektedirler (Acar, 2006: 23). Tüketilen toplam tarımsal üretim ile üretilen tarımsal üretim arasındaki farka pazarlanabilir fazla adı verilir. Ekonomik büyümeyi sağlayabilmek için pazarlanabilir fazlanın artırılması gerekmektedir (Thirlwall, 2003: 191). Tarım sadece tarım alanında çalışan iş gücünü değil aynı zamanda bu sektörün dışında çalışan diğer tüm iş gücüne gerekli gıdayı sağlamaktadır. Tarım dışı alanlarda çalışan iş gücünün beslenmesi önemli bir noktadır. Rostow kalkınma aşamaları yaklaşımlarında, ekonomik kalkınmanın temel aşamasını tarımsal devrim olarak görmektedir (Rostow, 1980: 25). Tarımın ekonomik büyüme de etkisi şu şekilde tanımlanabilir. Tarım eğer milli gelir içinde büyük bir paya sahip ise ve bu sektörün gelişimi hızlı ise, tarımın iktisadi büyümeye etkisi o kadar büyüktür. Tam tersi olarak ne kadar küçük ise iktisadi büyüme de o kadar küçüktür (Kazgan, 1966: 251). Gelişim gösteren ülkeler sanayi alanında yatırımlar yapmaktadırlar. Bu ülkeler kurdukları sanayilerde genellikle tarımdan sağladıkları ham maddeleri işlemektedirler. Örneğin salça üretimi için domates, kumaş üretimi için pamuk ile yün, ayakkabı üretimi için deri gibi ürünler tarım sektöründen temin edilmektedir. Bu örnekler sanayi sektörü için tarımın önemini göstermektedir (Boz, 2004: 141). iktisadi büyümenin meydana gelebilmesi için zorunlu olan yatırım ürünlerinin ithal edilmesi büyük oranla tarım ürünlerinin ihracatı ile gerçekleşebilir (Thirlwall, 2003: 194). Gelişmekte olan ülkelerin sahip oldukları doğal ve tarımsal kaynaklar ekonomik büyüme için büyük avantaj sağlamaktadır. Eğer gelişmekte olan bir ülke yer altı kaynaklarına sahip değilse, yapacağı sanayi üretiminde sermaye ve ara mal ithalatını yapmak için tarımsal ihracat yapmalıdır (Gillis vd., 1987: 482).

Kaldor, sanayideki büyümenin sadece sanayi sektörünü değil aynı zamanda yaratacağı iş olanakları ile diğer sektörlerinde verimliliğini ve gelişimini sağlamaktadır. Bundan dolayı Kaldor, sanayi sektöründeki büyümeyi iktisadi büyümenin motoru olarak görmektedir (Choi, 1983: 148-150). Kaldor ihracat alanında meydana gelecek olan büyümenin hızı ile ekonomik anlamda düşük verimliliğe sahip olan alanlardan sanayi sektörüne iş gücü aktarımı olacağını ve bundan dolayı verimlilik bakımından artışın olacağını savunmaktadır (Şimşek,1995:150). Sanayi sektörü ve sanayi üretimi arasındaki ilişki iktisat alanında en dikkat çeken konulardan biri olmuştur. İkinci dünya savaşı sonrasında ülkelerin savaşın yıkıntılarından sıyrılıp toparlanması ve endüstriyel toplum, diğer bir değişle modern toplum haline dönüşme amacı, ilgili alanda yapılan çalışmalara ivme kazandırmıştır. İkinci dünya savaşı sonrasında az gelişmiş ülkeler hızlı bir şekilde büyüme ve kalkınmalarını sanayileşmeye bağlamıştır (Arısoy, 2013: 143). Verdom yasasında sanayi üretiminde meydana gelen 1 birimlik artışın sağladığı ölçek ekonomisi sayesinde işgücü verimliliğine olumlu katkı sağlayacaktır. Verdom yasası endüstri içindeki artan getirinin varlığının temel argümanı bir ülkedeki endüstriyel büyümenin üretim maliyetlerinde düşüş sağlayarak verimliliği artıracağını 
savunmuştur. Buradan yola çıkarak sanayi sektöründe artan getiri sayesinde işgücü verimliliği ve sanayi üretimi arasında pozitif bir ilişki olduğu savunulmuştur (Ener ve Arıca, 2011).

\section{PANEL VERI REGRESYON MODELLERININ TAHMINI}

Panel kelimesi Flemenkçe kökenli bir kelime olup dikdörtgen şeklindeki tahta anlamını içermektedir (Kunst, 2011: 1). iktisadi çalışmalar yapılırken çeşitli veriler kullanılmaktadır. Kullanılan verinin türüne uygun modeller kullanılarak veriler incelenebilir. Örneğin zaman serisi verileri farklı, yatay kesit verileri ile farklı çalışmalar yapılmaktadır (Pazarlıoğlu ve Gürler, 2007: 3).

Panel veri kullanılan çalışmalarda genellikle üç gaye vardır. İlk gaye birimler arası değişkenliği veya her bir birimin zaman içinde değişkenliğini belirlemektir. Bundan dolayı, hem belli değişkenliklerin genişliğini hem de bu değişkenliklerin ilerleyişini izleyebiliriz. İkinci gaye, bu değişkenlikleri diğer bazı değişkenler açısından açıklayabilmektir. Bu değişkenler cinsiyet gibi zamanla değişmeyeceği gibi, psikolojik olarak zamanla değişebilen sürekli yani sabit olmayan türden olabilir. Üçüncü gaye ise her bir birimin ilgili değişken bakımından kestirimini yapmaktır (Hsiao, 2003:89).

Gözlemler her dönem gözlenebilmişse 'dengeli' panel, bazı dönemler gözlenebilmişse 'dengesiz' panel olarak ifade edilmektedir (Dougherty, 2006: 409). Doğrusal panel veri modeli aşağıdaki (1) numaralı denklemde ifade edilmektedir.

$$
Y_{i t}=\beta_{0}+\beta_{1 i t} X_{1 i t}+\beta_{2 i t} X_{2 i t}+\ldots+\beta_{k i t} X_{k i t}+\varepsilon_{i t}, i=1, \ldots, N, t=1, \ldots, T .
$$

Bu modelde $N$ yatay kesit birimlerini, $T$ süreci temsil etmektedir (Pazarlığlu ve Gürler, 2007: 3). Burada $Y$ bağımlı değişken, $X$ bağımsız değişken $k$ adettir (Tüzüntürk, 2007: 3). Ayrıca, en küçük kareler (EKK) varsayımlarından olan hata teriminin ortalaması sıfır, varyansının ise sabit olduğu kabul edilmektedir. Kısaca; $E\left(\varepsilon_{i t}\right)=0$ ve $\operatorname{Var}\left(\varepsilon_{i t}\right)=\sigma_{\varepsilon}^{2}$ şeklinde ifade edilir.

\subsection{Panel Birim Kök ve Eş-bütünleşme Testleri}

Panel veri analizi, zaman serisi ve kesitlerin bir ayara getirilerek oluşturulmasından dolayı zaman serisi özelliklerini ve zaman serilerinde görülen sorunları da içermektedir. Zaman serisi verileri gibi değişkenlerin de birim köke sahip olup olmadığı, aynı seviyede birim kök içeren değişkenler arasında eş-bütünleşme olup olmadığı analiz edilmelidir. Bunun nedeni, durağan olmayan verilerin sahte regresyon içerdiği ve dolayısıyla sağlıksız sonuçlara neden olmaktadır. Bundan dolayı panel birim kök testleri ve panel eş-bütünleşme testleri uygulanır (Altunkaynak, 2007:15). Im, Peseran ve Shin, panel birim kök testinde Dickey Fuller (ADF) test istatistiğini paneldeki her bir birim için ADF hesaplayarak, ADF'lerin ortalama test istatistiğine bakmaktadır. Panel birim kök testinin uygulanması için $N$ yatay kesit ve $T$ zaman serisi olmak üzere, $y_{i t}$ birinci dereceden otoregresif süreç:

$$
\Delta y_{i t}=\alpha_{i}+\beta_{i} y_{i, t-1}+\varepsilon_{i t}, \quad i=1, \ldots, N, t=1, \ldots, T
$$

olarak tanımlanmaktadır. Kurulan hipotezler;

$H_{0}: \beta_{i}=0$, bütün $i$ değerleri için,

$H_{1}: \beta_{i}<0 \quad i=1,2, \ldots, N_{1}, \quad \beta_{i}=0, i=N_{1}+1, N_{1}+2, \ldots, N$

şeklinde olup $H_{0}$ hipotezinin ret edilmemesi panel birim kökün olduğunu, alternatif hipotezin ret edilmemesi ise panel birim kökün olmadığı anlamına gelmektedir. Im, Pesaran ve Shin, "birim kök mevcut değildir" hipotezini $t$-bar istatistiği ile incelemektedir (Choi, 2001:260).

Panel verilerde uygulanan eş-bütünleşme testi, " $H_{0}$ : eş-bütünleşme mevcut değildir" şeklindeki yokluk hipotezini analiz eder. Pedroni eş-bütünleşme testinde birinci adım, hipotezde ön görülen eş-bütünleşme regresyonundan hata terimlerini elde etmektedir. Genel olarak, $t=1, \ldots, T ; i=1, \ldots, N$ ve $m=1, \ldots, M$ olmak üzere eş-bütünleşme modeli aşağıda yere alan model şeklinde yazılır.

$$
y_{i, t}=\alpha_{i}+\delta_{i t}+\beta_{1 t} x_{1 i, t}+\beta_{2 t} x_{2 i, t}+\ldots+\beta_{m t} x_{m i, t}+\varepsilon_{i, t}
$$

Burada (3) eşitliğinde; $T$ zaman genişliğini, $N$ paneldeki birey sayısını, $M$ değişken sayısını gösterir. Panelin $N$ tane farklı bireyi olduğundan, her biri $M$ değişkene sahip $N$ farklı denklemin olduğu kabul edilebilir. Eğim katsayıları olan $\beta_{1 i}, \beta_{2 i}, \ldots, \beta_{M i}$, panelin bireyleri süresince değişmesine olanak sağlamaktadır. $\alpha_{i}$, bireye özel sabit ya da bireyler boyunca değişimine olanak sağlayan verilerin sabit etki değişkenidir. Ayrıca bazı uygulamalar, paneldeki özel zaman akımını kullanmayı tercih edebilir. Bu durum $\delta_{i t}$ ile gösterilir. Aynı zamanda $\alpha_{i}$ 'nin göz ardı edilerek kullanımı yaygındır (Altunkaynak, 2007: 26). Panel veri analizinde uygulanan iki temel test vardır. Bunlar; Sabit Etki Modeli (Fixed Effect Model= FEM) ve Rassal Etki Modeli (Random Efffect Model = REM). 


\subsection{Sabit Etki Modeli}

Eğim katsayılarının sabit olduğu kabul edilen Sabit Etki Modelinde bireyler, hane halkları, şirketler gibi birimler arasındaki değişikliğin sabit terimdeki değişiklikler ile açıklanabileceği varsayılmaktadır. Bu modelde sabit etki, gruba özgü sabit terim olarak ifade edilir. Sabit etki, burada birimlerin (bireylerin, hane halklarının, şirketlerin v.b) göre değişim gösterebileceği ancak zamana göre sabit kalacağını belirtmektedir (Greene, 2003: 285).

Sabit Etki Modeli, birimlerin kendi içindeki değişikliklerin sabit terimdeki değişiklikler yardımıyla ulaşılabileceğini kabul etmektedir. Bundan dolayı panel veri modeli, EKK Kukla Değişken Modeli (Least Square Dummy Variable = LSVD) olarak tanımlanan yöntem ile tahmin edilmektedir. (1) numaralı panel veri modeli ele alındığında;

$$
\beta_{0 i t}=\beta_{0 i}, \quad \beta_{1 i t}=\beta_{1}, \quad \beta_{2 i t}=\beta_{2}, \quad \beta_{\text {kit }}=\beta_{k},
$$

şeklinde olduğu varsayılmaktadır. Burada dikkat edilecek olursa, sadece sabit parametreler değişmektedir. Sabit terimin zaman içinde değişmediğini buna karşın yatay kesit durumunda farklılıklar gösterdiği açıktır. Yani, zaman genişliği sabit tarafından korunmasına rağmen bireyler arasındaki davranışların farklııılar gösterdiğini belirtmektedir. (1) numaralı panel veri modeli yeniden göz önüne alındığında;

$$
Y_{i t}=\beta_{0 i}+\beta_{1 i t} X_{1 i t}+\beta_{2 i t} X_{2 i t}+\ldots+\beta_{k i t} X_{k i t}+\varepsilon_{i t}
$$

şeklinde yazılır. Bu model $\beta_{0 i}$ ifadesine göre yeniden yazılırsa;

$$
\begin{aligned}
& Y_{i t}=\beta_{01} D_{1 i}+\beta_{02} D_{2 i}+\ldots+\beta_{0 N} D_{N i}+\beta_{2 i t} X_{2 i t}+\ldots+\beta_{k i t} X_{k i t}+\varepsilon_{i t} \text { (7) } \\
& Y_{i t}=\sum_{j=1}^{N} \beta_{0 j} D_{j i}+\sum_{k=1}^{K} \beta_{k} X_{k t}+\varepsilon_{i t} \\
& D_{1 i}=\left\{\begin{array}{cc}
1, & i=1 \\
0, & \text { aksidurumda }
\end{array}, \ldots, D_{1 N}=\left\{\begin{array}{cr}
1, & i=N \\
0, & \text { aksi durumda }
\end{array}\right.\right.
\end{aligned}
$$

(Pazarlıoğlu ve Gürler, 2007: 4)

Bu modelde (5-7), $K$ tane açıklayıcı değişken ve $N$ tane yatay kesit birimi mevcuttur. Burada önemli olan sabit etkiler modeline birim etkileri eklerken, gölge değişkeni tuzağına düşmemek için de birim sayısından $(N-1)$ gölge değişken kullanılmalıdır. Öte yandan $N$ sayıda gölge değişken kullanılacaksa da modele sabit terim alınmamalıdır (Tatoğlu, 2012: 81).

\subsection{Rassal Etki Modeli}

Rassal etki modeli, gözlenemeyen bireysel etkileri ile bağımsız değişkenler arasında ilişki kurmasına imkân sağlamaktadır. Bu halde regresyon modelimizde sabit etki modelinde birimler arasındaki farklılıklar ve parametrik değişimler tamamen doğru olarak modellenmektedir. Şayet bireysel etki modelinde yer alan bağımsız değişkenler arasında tam bir ilişki yok ise, birimlere has sabit terimlerin, birimlere göre rassal olarak dağıldığını kabul eden rassal etki modelinin kullanılması doğru olur (Greene, 2003: 293).

Birimler arası zamanla ortaya çıkan farklııklar, rassal etki modelinde hata teriminin bir parçası olarak varsayılmaktadır. Asıl hedef, sabit etki modellerinde meydana gelen serbestlik derecesini büyük oranda düşürmektir. Bunun sebebi rassal etki modelinin önemli olan birimlere ya da birime ve zamana özgü hat bileşenlerin bulunmasıdır. Öte yandan rassal etki modeli, hem örneklemdeki birimler ve zamana göre ortaya çıkan farklııkları hem de örneklem dışında oluşan etkileri dikkate almaktadır (Pazarlıoğlu ve Güler, 2007: 5).

Yukarıda belirtilen sabit ve rassal etki modellerinden hangisinin panel analizi için uygun olduğu test etmek için Hausman testi kullanılmaktadır.

\subsection{Hausman testi}

Birim ya da birim ve zaman farklılıklarını oluşturan katsayıların, yani rassal etki modelinin hata terimi bileşenlerinin modeldeki bağımsız değişkenlerden bir ilişkiye sahip olmadığı hipotezinin geçerliliği, Hausman test istatistiği ile analiz edilebilmektedir (Pazarlıoğlu ve Güler, 2007: 5). Hausman test istatistiği rassal ve sabit etki modellerinden hangisinin tercih edileceği konusunda yardımcı olur. Hausman testine ait hipotezleri aşağıda verildiği gibidir.

$H_{0}=$ Rassal etkiler mevcuttur

$H_{1}=$ Rassal etkiler mevcut değildir

(Çakır ve Küçükkaplan, 2012: 78-79).

Hausman Test istatistiği $k$ serbestlik dereceli ki-kare dağılımı göstermektedir (Pazarlığlu ve Gürler, 2007). Test istatistiğinin değeri kritik değeri olan $p$ değerimizden küçük olduğunda $H_{0}$ hipotezi kabul görür. Bu halde rassal etki modeli tercih edilir. 
Eğer test istatistiğinin değeri kritik değeri olan $p$ değerinden büyük olması durumunda $H_{0}$ hipotezi kabul görmez. Bu durumda sabit etki modeli tercih edilir (Çakır ve Küçükkaplan, 2012).

\section{VERI SETI VE EKONOMETRIK METODOLOJi}

Uygulama için 1993-2017 verileri Dünya Bankası (Worldbank) resmi web adresinden oran olarak alınmıştır. Verilerin durağanlığı, panel veri birim kök testleri ile analiz edilmiştir. Durağan olmayan verilerle yapılacak olan tahminin yanlış sonuçlar vereceği için, durağanlık zaman serileri için önemli bir kavramdır. Veriler durağan hale getirildikten sonra panel veri analizi aşamaları yapıldı. Tarım ve sanayi sektöründe istihdamın iktisadi büyüme üzerindeki etkisini analiz etmek için OECD ülkelerinden (1993-2017 yılları arasında bu alanda en büyük gelişmeyi sağladığı düşünülen üç ülke ile Türkiye arasında bir kıyaslama tercihinden bu ülkeler seçilmiştir)Almanya, Belçika, Kanada ve Türkiye ülkeleri seçilmiştir. Modelde kullanılan değişkenlerin kısaltmaları aşağıda yer aldığı gibidir.

GSYiH= Gayrisafi Yurtiçi Hasıla (iktisadi Büyüme)

iSTARIM= Tarım sektöründe istihdam

ISSANAYI= Sanayi sektöründe istihdam

Modelde GSYIH bağımlı değişken, ISTARIM ve ISSANAYi bağımsız değişkenlerdir. Değişkenler arasındaki ilişkiyi analiz etmek için aşağıdaki panel veri modeli kullanılmıştır.

$$
G S Y \dot{\mathrm{I}} H_{i t}=\beta_{0 i t}+\beta_{i t} \dot{\mathrm{I} S T A R I M} \mathrm{i}_{\mathrm{i} T}+\beta_{i t} \dot{\mathrm{I} S S A N A Y \dot{\mathrm{I}}_{i t}}+\varepsilon_{i t}
$$

Burada (8) denkleminde $i=1, . .4$ ülkeyi, $t=1993, \ldots, 2017$ zaman aralığını temsil etmektedir. Model kurulduktan sonra yapılan panel veri analiz sonuçları aşağıda başılıklar halinde verilmiştir.

\section{UYGULAMA VE BULGULAR}

\subsection{Panel Birim Kök Tablosu}

Zaman serilerinde durağanlık, varyansın zamana bağlı olarak bir değişimin olmadığını ifade eder (iş̧leyen ve ark., 2017). Zaman serisi verileri kullanılan çalışmalarda serilerin durağan olmaları önemlidir. Zaman serileri analizinde, durağan olmayan seriler kullanıldığında, kullanılacak modelin sonuçları gerçekçi olmamakta ve durağan olmayan serilerin kullanılması modele tabi tutulan değişkenler arasında sahte ilişkiye neden olmaktadır. Bir değişkenin durağan olup olmadığını veya durağanlık derecesini belirlemek için kullanılan en genel analiz birim kök testidir (Gujarati, 2004). Ekonometrik çalışmalarda, birim kök testleri büyük önem taşır ve birçok alanda kullanılır. Aşağıda panel birim kök testleri ve sonuçları verilmiştir.

Tablo 1: Panel Birim Kök Test Sonuçları

\begin{tabular}{|l|c|c|c|c|}
\hline \multirow{2}{*}{ GSYiH } & \multicolumn{2}{|c|}{$\mathbf{I ( 0 )}$} & \multicolumn{2}{|c|}{$\mathbf{I ( 1 )}$} \\
\cline { 2 - 5 } & t-istatistik & p-olasılık & t istatistik & p olasılık \\
\hline Levin, Lin\&Chu & -4.314 & 0.000 & -7.584 & 0.000 \\
\hline Im,Peseron and Shin W-stat & -3.848 & 0.001 & -6.450 & 0.000 \\
\hline ADF Fisher Ki-kare & 29.705 & 0.002 & 48.676 & 0.000 \\
\hline PP Fisher Ki-kare & 24.502 & 0.001 & 62.175 & 0.000 \\
\hline Breitung t-stat & -3.949 & 0.000 & -3.707 & 0.000 \\
\hline
\end{tabular}

\begin{tabular}{|l|c|c|c|c|}
\hline iSTARIM & \multicolumn{2}{|c|}{$\mathbf{I ( 0 )}$} & \multicolumn{2}{c|}{ I(1) } \\
\hline & t istatistik & p olasilık & t istatistik & p olasılık \\
\hline Levin, Lin\&Chu & -0.58147 & 0.2805 & -6.91539 & 0.0000 \\
\hline Im,Peseron and Shin W- stat & 1.62556 & 0.9480 & -7.57782 & 0.0000 \\
\hline ADF Fisher Ki-kare & 2.34938 & 0.9684 & 59.0868 & 0.0000 \\
\hline PP Fisher Ki-kare & 2.30193 & 0.9703 & 58.8246 & 0.0000 \\
\hline Breitung t-stat & -1.36308 & 0.0864 & -5.60409 & 0.0000 \\
\hline
\end{tabular}

\begin{tabular}{|l|c|c|c|c|}
\hline iSSANAYi & \multicolumn{2}{|c|}{$\mathbf{I ( 0 )}$} & \multicolumn{2}{c|}{$\mathbf{I ( 1 )}$} \\
\hline & $\mathbf{t}$ istatistik & p olasılık & t istatistik & p olasılık \\
\hline Levin, Lin\&Chu & -1.68012 & 0.0465 & -9.52834 & 0.0000 \\
\hline Im,Peseron and Shin W- stat & 1.11158 & 0.8668 & -7.95334 & 0.0000 \\
\hline
\end{tabular}




\begin{tabular}{|l|l|l|l|l|}
\hline ADF Fisher Ki-kare & 5.17217 & 0.7390 & 62.2425 & 0.0000 \\
\hline PP Fisher Ki-kare & 8.74944 & 0.3639 & 62.4544 & 0.0000 \\
\hline Breitung t-stat & 0.45534 & 0.6756 & -6.95226 & 0.0000 \\
\hline
\end{tabular}

Tablo-1'de değişkenlerin durağanlık durumu verilmiştir. Panel birim kök testleri için; Levin, Lin\&Chu, Im, Peseron and Shin Wstat, ADF Fisher Ki-kare, PP Fisher Ki-kare ve Breitung t-stat testleri kullanılmıştır. Verilerle işlem yapabilmek için durağan olmaları gerekmektedir. Karşılaştırmalı birim kök testlerin kullanılması, sonuçların daha sağlıklı analiz edilmesini sağlayacağı için, bu beş panel birim kök testi kullanılmıştır. Tablo-1 analiz edildiğinde; GSYiH'nın düzey seviyede durağan olduğu tüm birim kök testlerinin olasılık değerlerinde görülmektedir. ISTARIM ve ISSANAYI'nin ise düzey seviyede birim köke sahip olduğu, yani durağan olmadığı görülmüştür. Birinci farkları alındığında olasılık değerleri, kritik değer olan 0.05 'ten küçük olduğundan, bu değişkenlerin birinci seviyeden durağan oldukları görülmüştür.

Modeldeki değişkenlerin durağanlıkları analiz edildikten sonra durağan olan değişkenler, panel eş-bütünleşme testleri ile incelenerek sonuçları aşağıdaki tabloda verilmiştir.

\subsection{Panel Eş-Bütünleşme Tablosu}

Eş-bütünleşme analizi, uzun dönem serilerinde fark alındığında oluşan bilgi kaybını gidermekte ve çözümü için büyük bir kolaylık sağlamaktadır. Değişkenler arasında uzun dönem ilişkinin mevcut olup olmadığını incelemek için, eş-bütünleşme testleri kullanılmaktadır. Aşağıda panel eş-bütünleşme test sonuçları verilmiştir.

Tablo 2: Panel Eş-Bütünleşme Test Sonuçları

\begin{tabular}{|l|c|c|}
\hline Pedroni Eş-bütünleşme Testi & Test İstatistiği & p olasılık değeri \\
\hline Panel v-istatistiği & 0.301181 & 0.3816 \\
\hline Panel rho-istatistiği & -2.469375 & 0.0068 \\
\hline Panel PP-isstatistiği & -5.943152 & 0.0000 \\
\hline Panel ADF-Istatistiği & -4.823415 & 0.0000 \\
\hline Group rho-istatistiği & -2.575134 & 0.0050 \\
\hline Group PP-ístatistiği & -8.444296 & 0.0000 \\
\hline Group ADF-istatistiği & -3.945352 & 0.0000 \\
\hline
\end{tabular}

\begin{tabular}{|l|c|c|}
\hline Kao Eş-Bütünleşme Testi & Test İstatistiği & p olasılık değeri \\
\hline ADF & -3.165569 & 0.0008 \\
\hline Atıklar varyans & 1.088586 & \\
\hline HAC varyans & 0.169667 & \\
\hline
\end{tabular}

\begin{tabular}{|l|c|c|}
\hline Johansen- Fisher Eş-Bütünleşme Testi & Test İstatistiği & p olasılık değeri \\
\hline Yok & 61.79 & 0.0000 \\
\hline En fazla 1 & 18.67 & 0.0167 \\
\hline En fazla 2 & 21.90 & 0.0051 \\
\hline
\end{tabular}

Panel veri analizi için Tablo-2'de yer alan, Pedroni Eş-bütünleşme testi, Kao Eş-bütünleşme testi ve Johansen-Fisher Eşbütünleşme testleri kullanılmıştır. Test sonuçları analiz edildiğinde; Pedroni Eş-bütünleşme testinde yer alan Panel v-istatistiği dışında diğer tüm testlerinde eş-bütünleşme olduğu görülmektedir. Bu sonucu, tüm testler için $p$ olasılık değerlerinin kritik değer olan 0.05 'ten küçük olmasından görmekteyiz. Bundan dolayı, değişkenler arasında uzun dönemli bir ilişkinin mevcut olduğu görülmektedir. Değişkenler arasında uzun dönemli bir ilişkinin olduğu tespit edildikten sonra durağan verilerle modelin tahminine geçilmiştir.

\subsection{Panel Veri Analizi Klasik Modelin Tahmin Sonuçları}

Neo-klasik büyüme teorilerinin temel öngörüsü ülkelerin çıktılarındaki artış oranının zaman içerisinde birbirine yakınsayacağıdır. Bu sonuç, kişi başına düşük gelirli ülkelerin yüksek gelirli ülkelere göre daha hızlı büyüyecekleri öngörüsü nedeniyle ortaya atılmıştır. Bu da temelde iki varsayıma dayanır. Bunlardan birincisi, teknolojik değişmenin dışsal olduğu ve ikincisi ise, ülkeler arasında sabit olduğu varsayımıdır. 
Tablo 3: Panel Klasik Model Test Sonuçları

\begin{tabular}{|l|l|l|l|}
\hline Değişkenler & Katsayı değeri & t istatistik değeri & p olasılık değeri \\
\hline SABIT & 0.055085 & 0.624385 & 0.5343 \\
\hline DiSTARIM & 0.073585 & 3.152002 & 0.0023 \\
\hline DiSSANAYi & 0.094440 & 2.826340 & 0.0061 \\
\cline { 1 - 2 }$R^{2}$ & 0.689578 & & \\
\cline { 1 - 2 } D-W değeri & 2.34 & & \\
\cline { 1 - 2 } F İstatistik & 8.655238 & \\
\cline { 1 - 2 } F olasılık & 0.000419 &
\end{tabular}

Bağımlı değişken: GSYiH

Tablo 3'de panel veri analizinde klasik model sonuçları görülmektedir. Tablo-3, tahmin sonuçları yüzde beş anlam düzeyinde analiz edildiğinde, tarım ve sanayi alanında istihdamın istatistiksel açıdan anlamlı olduğu görülmektedir. Modelin determinasyon katsayısı yaklaşık yüzde altmış sekiz (0.68) olarak hesaplanmıştır. Bu da gelir değişkeninin tüketimde oluşan değişimlerin yaklaşık olarak altmış sekizini açıkladığı anlamına gelmektedir. Bu modelde, tarım alanındaki istihdamda meydana gelen bir birimlik artış GSYiH'da 0.07 birimlik pozitif bir artışa neden olmaktadır. Aynı şekilde, sanayi alanındaki istihdamda meydana gelen bir birimlik artış GSYiH'da 0.09 birimlik pozitif bir artışa neden olmaktadır. Aynı şekilde $F$-olasılık değeri, modelin bir bütün olarak anlamlı olduğunu göstermektedir.

Klasik model analizi yapıldıktan sonra Panel veri analizi için sabit etki ve rassal etki modellerin tahmini yapılmıştır ve bu sonuçlar aşağıdaki tabloda verilmiştir.

\subsection{Panel Veri Analizi Sabit Etkili Modelin Tahmin Sonuçları}

Sabit etkiler modeli her bir yatay kesit birimi için farklı bir sabit değer meydana getirmektedir. Sabit etkiler modelinde $\beta$ ile gösterilen eğim katsayılarının değişmediği, fakat sabit katsayıların sadece kesit verileri arasında veya sadece zaman verileri arasında veya her iki veri içinde değişme söz konusu olduğunda başvurulan bir yöntemdir. Yani panel veri setinde kesitler arasında fark olduğunda, zamana bağı bir farklılaşma yoksa bu regresyon modeli tek yönlü ve kesite bağlı sabit etkiler modeli olarak isimlendirilir. Değişim sadece zamana bağlı olarak meydana geliyorsa, bu tür modeller tek yönlü zamana bağlı sabit etkiler modeli olarak isimlendirilir. Eğer panel verilerde hem zamana ve hem de kesite göre bir farklılaşma varsa, bu modellere çift yönlü sabit etkiler modeli denir. Ancak panel veri analizlerinde çoğunlukla zaman etkisinden çok kesit etkisi araştırıldığından panel veri modelleri genellikle tek yönlü modellerdir (Hsiao, 2002:30).

Tablo 4: Sabit Etkili Model Test Sonuçları

\begin{tabular}{|l|c|c|c|}
\hline Değişkenler & Katsayı değeri & t istatistik değeri & p olasılık değeri \\
\hline SABIT & 0.067086 & 0.767359 & 0.4454 \\
\hline DiSTARIM & 0.064705 & 3.161815 & 0.0023 \\
\hline DiSSANAYi & 0.08112 & 3.508148 & 0.0008 \\
\hline$R^{2}$ & 0.620020 & & \\
\cline { 1 - 2 } D-W değeri & 2.469620 & & \\
\cline { 1 - 2 } F İstatistik & 4.484704 & & \\
\cline { 1 - 2 } F olasılık & 0.001313 & &
\end{tabular}

Tablo-4'te yatay kesit verileri ile ağırlıklandırılarak, White Cross Section ile değişen varyans sorununu göz önüne alacak şekilde sabit etki modeli tahmini yapılmıştır. Tahmin sonuçları yüzde beş anlam seviyesinde analiz edildiğinde, tarım ve sanayi alanında istihdamın istatistiksel olarak anlamlı olduğu görülmektedir. Modelin determinasyon katsayısı yaklaşık yüzde altmış iki (0.62) dir. Bu durum, gelir değişkeninin tüketimde oluşturduğu değişimlerin yaklaşık altmış ikisini açıkladığı anlamına gelmektedir. Bu modelde, tarım alanındaki istihdamda meydana gelen bir birimlik artış GSYiH'da 0.06 birimlik pozitif bir artışa neden olmaktadır. Aynı şekilde, sanayi alanındaki istihdamda meydana gelen bir birimlik artış GSYiH'da 0.08 birimlik pozitif bir artışa neden olmaktadır.

\subsection{Panel Veri Analizi Rassal Etkili Modelin Tahmin Sonuçları}

Rassal etkili (random effects) modeller, kesitlere ve zamana bağı bir şekilde oluşan değişiklikler modele hata teriminin bir bileşeni olarak dahil edilmeleri halinde kullanılabilen bir modeldir. Rassal etkili modellerin sabit etkili modellere göre daha elverişli olmasının sebebi, bu modellerde serbestlik derecesi kaybının ortadan kalkmış olmasıdır. Bunun yanında rassal etkiler modeli, modele örneklem dışındaki etkilerin de dahil edilmesine imkan sağlamaktadırlar. 
Tablo 5: Rassal Etkili Model Test Sonuçları

\begin{tabular}{|l|c|c|c|}
\hline Değişkenler & Katsayı değeri & t istatistik değeri & p olasılık değeri \\
\hline SABiT & 0.055085 & 0.631568 & 0.5296 \\
\hline DiSTARIM & 0.053585 & 3.188264 & 0.0021 \\
\hline DiSSANAYi & 0.079444 & 2.858856 & 0.0055 \\
\hline$R^{2}$ değeri & 0.589578 & & \\
\cline { 1 - 2 } D-W değeri & 2.340062 & & \\
\cline { 1 - 2 } F İstatistik değeri & 8.655238 & & \\
\cline { 1 - 2 } F olasılık değeri & 0.000419 &
\end{tabular}

Tablo-5'te yatay kesit verileri ile ağırlıklandııılmış ve White Cross Section ile değişen varyans problemini gözönüne alan rassal etki modeli tahmini yapılmıştır. Tahmin sonuçları yüzde beş anlam seviyesinde analiz edildiğinde, tarım ve sanayi alanında istihdamın istatistiki olarak oldukça anlamlı olduğu görülmektedir. Modelin belirlilik katsayısı yaklaşık olarak yüzde elli sekiz (0.58) olarak bulunmuştur. Yani bağımsız değişkenler, bağımlı değişken olan GSYiH'daki değişimlerin yaklaşık yüzde elli sekizini açıklamaktadır. Bu modelde, tarım alanındaki istihdamda meydana gelen bir birimlik artış GSYiH'da 0.05 birimlik pozitif bir artışa neden olmaktadır. Aynı şekilde, sanayi alanındaki istihdamda meydana gelen bir birimlik artış GSYiH'da 0.07 birimlik pozitif bir artışa neden olmaktadır.

Yapılan analiz sonuçlarına göre, panel veri modelleri olan Sabit Etki Modeli ve Rassal Etki Modelinde verilerimiz gayet uyumlu olduğu görülmektedir. Bu durumda Hausman test istatistiği, rassal etki ya da sabit etki modelinden hangisinin tercih edilmesi gerektiği konusunda yardımcı olacaktır.

\subsection{Haussmann Test Sonuçları}

Panel veri modelinin tahmininde havuzlanmış (pooled) regresyon sabit etkiler (fixed effects) ve rastsal etkiler (random effects) olmak üzere üç yaklaşım vardır. Eğer ihmal edilmiş sabit etkilerden ve rastsal etkilerden yatay kesit değişkenlerinin bağımsız olduğu kesin ise pooled regresyonu kullanmak daha doğru sonuçlar verecektir. Bunun için de öncelikle Breusch-Pagan (B-P) testinin yapılması gerekecektir. B-P testi ile birim etkilerinin varyansının sıfır olması durumunda rastsal etkili modelin havuz modeline dönüşeceği boş hipotezi sınanmaktadır. Modelin OLS (pooled-havuzlanmış) regresyon ile tahmin edilemediği durumda, analizde rastsal etkiler mi yoksa sabit etkiler yaklaşımının mı kullanılacağı ile ilgili karar vermek için Hausman testi kullanılır.

Tablo 6: Haussmann Test Sonuçları

\begin{tabular}{|l|c|c|c|}
\hline Test özeti & Ki kare & ki-kare. d.f. & p-olasılık değeri \\
\hline Yatay-kesit rastsal & 4.491078 & 2 & 0.1059 \\
\hline
\end{tabular}

Tablo- 6 analiz edildiğinde, yokluk hipotezi rassal etki şeklinde olan Hausman test istatistiğini yüzde beş anlam düzeyinde analiz edildiğinde yokluk hipotezini kabul etmektedir. Yani Hausman test istatistiği, sabit etki modelini değil, rassal etki modelini kullanılması gerektiğini ifade etmektedir. Bu yüzden en uygun modelin rassal etki modeli olduğu gerçeğine ulaşılmaktadır. $p$ olasılık değerinin yüzde beş değer olan kritik değerden yüksek olması bu sonucu verir.

\section{SONUÇ VE DEĞERLENDIRME}

Hükümetlerin istihdamı destekleyecek projeler ile ekonomiyi nasıl pozitif yönde etkileyebileceği gelişmiş ülkelerde açık şekilde görülmektedir. Özellikle tarım ve sanayi alanında oluşan gelişimin ülkelerin ekonomik olarak büyük bir güce sahip olduklarını göstermektedir. Bu alanda oluşacak istihdamın ülkedeki işsizlik oranını düşürmekle birlikte ekonomik kalkınmaya da büyük etki yapmaktadır.

Bu çalışmada, dört OECD ülkesi için tarım sanayi sektöründe istihdamın iktisadi büyüme üzerindeki etkisi panel veri analizi kullanılarak incelendi. 1993-2017 yıllarını içeren yıllık verilere, önce panel birim kök testleri yapıldı. Testlere göre, büyüme oranı düzey seviyede durağan iken, tarım ve sanayi sektöründe istihdamın ise birinci farkı alındığında durağanlaşmaktadır. Veriler aynı seviyede durağan hale getirildikten sonra değişkenler arasında ilişki olup olmadığını belirlemek için, önce panel eş-bütünleşme testleri uygulandı. Bu analizin sonucunda tarım ve sanayi sektöründe istihdam ile iktisadi büyümenin uzun dönemde eş-bütünleşik olduğu sonucu elde edildi. Ayrıca modelin uzun dönem katsayı sonuçlarına göre, tarım sektöründe istihdamın \% 1 artması, iktisadi büyümeyi \% 0.07 olumlu etkilemektedir. Aynı şekilde sanayi sektöründe istihdamın \% 1 artması, ekonomik büyümeyi \% 0.09 pozitif yönde etkilemektedir. Modelde yer alan verilerin istikrarlı olması, daha güvenilir yorumlar yapılmasına olanak tanımaktadır. Daha sonra panel veri analizinde sabit ve rassal etki testleri yapıldı. Test sonuçları klasik test modelindeki gibi olumlu sonuçlar verdi. Son olarak, sabit veya rassal etki modellerinden hangisinin panel analizi 
için uygun olduğunu analiz etmek için Hausman testi uygulandı. Hausman test sonuçlarına göre panel veri analizi için uygun testin rassal etki modeli olduğu sonucuna varıldı.

Elde edilen bulgulara göre, tarım ve sanayi sektöründe istihdamın artması bu alanın üretim konusunda ilerlediğini ve bunun da ekonomik büyümeyi olumlu etkilediği görülmektedir. Tarımın ham madde ve yaşamın sürdürülebilir olması için büyük öneme sahip olduğu gerçeği ve bu sektörde meydana gelen istihdamın ülkeye ekonomik kalkınmada pozitif etki yaptığı, yapılan analizler sonucu görülebilir. Özellikle tarım ülkesi olan Türkiye için büyük önem arz eden tarımın son zamanlarda kan kaybediyor olması, tarım ürünlerinin ithal edilmesine sebep olmaktadır. Bu durumun önüne geçilmesi için;

- Ithalat temelli politikaların yerine yerli ürün üretim destekli politikalar üretilmesi,

- Üreticide ucuz olan ürünün tüketiciye pahalı bir şekilde yansımasına neden olan aracıları denetleyecek politikalar üretilmesi,

- $\quad$ İklim değişikliğine uygun politikalarla çeşitli ürünlerin üretilmesinin sağlanması,

- Üreticiye teşvik programları sunulması gerekmektedir.

Bu tür yapılandırmalarla ülkede tarımın tekrar canlanacağı ve ekonomik büyümenin daha olumlu ilerleyeceği düşünülmektedir.

Dünya ülkelerinin artık teknoloji ve sanayi olarak mücadele ettikleri gerçektir. Bu alanda ilerleme kat eden ülkelerin ekonomik olarak da güçlü oldukları ve üretici ülkeler sınıfında oldukları görülmektedir. Türkiye'nin bu rekabet içinde yer edinebilmesi için, sanayi ve teknoloji alanında ilerleme sağlaması gerekmektedir. Bu ilerlemeyi sanayi alanında yatırımlara teşvik programları çıkararak ve teknolojik üretime yönelerek sağlayabiliriz. Bu bağlamda, teknolojik eğitimler verilmeli ve üretici bir gençlik yetiştirilmelidir. Türkiye' de mevcut işgücünün eğitim seviyesi bir aşama ilerletildiğinde istihdam sorunu çözülebilecek duruma gelir. Böylelikle sanayi sektöründe istihdamın artırılmasının büyük ölçüde sektörün ihtiyaçlarını karşılayacak düzeyde nitelikli işgücü yetiştirilebilmesine bağlı olduğu durumu ortaya çıkar.

\section{KAYNAKÇA}

Acar, M. (2006). DTÖ ve AB Işığında Türk Tarımının Geleceği. Orion, Yayınevi, Ankara.

Akyııdız, H. (2006). Türkiye'de istihdamın Analitik Dinamiği. Asil Yayın Dağııı, Ankara.

Altunkaynak, B. (2007). Sektörel Panel Veri Analizi Yaklaşımıyla Türkiye'nin AB Ülkelerine Imalat Sanayi Bakımından ihracatının Belirlenmesi. Doktora Tezi, Gazi Üniversitesi Fen Bilimleri Enstitüsü, 122s.

Arısoy, i. (2013). Kaldor Yasası Çerçevesinde Türkiye'de Sanayi Sektörü ve iktisadi Büyüme Ilişskisinin Sınanması. Eskişehir Osmangazi Üniversitesi iïBF Dergisi, 8(1), 143-162.

Boz, I. (2004). Tarım Sektörünün iktisadi Kalkınmadaki Rolü, İçinde, Kalkınma Ekonomisi: Seçme Konular. Ed: Sami Taban-Muhsin Kar, Ekin Kitabevi Yayınları, Bursa, 137-158.

Chol, I. (2001). Unit root tests for panel data. Journal of International Money and Finance, 20: 279-272.

Chol, K. (1983). Theories of Comparative Economic Growth. Iowa State University Press, Ames, lowa.

Çakır, H. M., Küçükkaplan, I. (2012). İşletme Sermayesi Unsurlarının Firma Değerleri ve Karlılığı Üzerindeki Etkisinin IMKB'de Işlem Gören Üretim Firmalarında 2002-2009 Dönemi Için Analizi. Muhasebe ve Finansman Dergisi, 69-86.

Damodar, N. Gujarati, (2004). Basic Econometrics. Newyork, The McGraw-Hill Comp., 2004.

Doğan, A. (2009). Ekonomik Gelişme Sürecine Tarımın Katkısı: Türkiye Örneği. Sosyal ve Ekonomik Araştırmalar Dergisi, Selçuk Üniversitesi, cilt 9, sayı 17, 365-392.

Dougherty, C. (2006). Introduction to Econometrics. New York: Oxford Universty Press.

Ener, M. , Arıca, F. (2011). Is the Kaldor's Law Valid for High Income Economies: A Panel Study. Research Journal of Economics, Business and ICT, 1, 60-64.

GIllıs, M., Dwight, H., Perkins, D. H., Roemer, M. ve Snodgrass, D. R. (1987). Economics of Development. Second Edition, W. W. Norton Company, New York.

Greene, W. H. (2003). Econometric Analysis. New Jersey: Prentice-Hall.

Hsıao, C. (2003). Analysis of Panel Data. Cambridge: Cambridge University Press.

İşleyen, Ş., Altun, Y. ve Görür, Ç. (2017). The Causality Relationship Between Interest Rate and Income with Investment in USA: 1965-2016. The Journal of Academic Social Science, 5, sayı:60, 146-163. 
Karaçor, Z. ve Saraç, T. B. (2011). Dış Ticaret ile Sanayi Sektörü Istihdam Oranı Arasındaki Kısa ve Uzun Dönem iliş̧kisi: Türkiye Örneği (19632009). Yönetim ve Ekonomi Yıl:2011 Cilt:18 Sayı:2 Celal Bayar Üniversitesi i.I.B.F. MANiSA.

Kazgan, G. (1966). Tarım Ekonomisi ve iktisadi Gelişme. İ. Ü. İktisat Fakültesi Yayını, İstanbul.

Korkmaz, E. (2016). Sanayi Sektöründe Gözyaşı Var. http://www.yeniçağgazetesi.com.tr/ sanayi-sektorunde- gozyasi-var-39272 yy.htm, son erişim tarihi: 28.08.2018.

Kunst, R. M. (2011). Econometric Methods for Panel Data.-Part I.

Parasız, i. (2008). Ekonomik Büyüme Teorileri. Ezgi Kitabevi, Bursa.

Pazarlığlu, M. ve Gürler, Ö. K. (2007). Telekomünikasyon Yatııımları ve Ekonomik Büyüme: Panel veri Yaklaşımı. 8. Türkiye Ekonometri ve İstatistik Konferansı (s. 1-10), İnönü üniversitesi, MALATYA.

Rostow, R. W. (1980). iktisadi Gelişmenin Merhaleleri. (Çeviren: Erol Güngör), Ikinci Baskı, Kalem Yayınları, İstanbul.

Şimşek, M. (1995). Türkiye'de Imalat Sanayi Üretimiyle Ekonomik Büyüme Arasındaki iliş̧kinin Kaldor Yaklaşımı Ile Analizi. Marmara Üniversitesi İktisadi ve İari Bilimler Fakültesi Dergisi, Cilt XI, Sayı 1-2, ss.141-156.

Taban, S. (2008). iktisadi Büyüme: Kavram ve Modeller. Ankara, Nobel Yayın Dağııım.

Tatoğlu, F. (2012). Panel Veri Ekonometrisi: Stata Uygulamalı. i̇stanbul: Beta.

Terzi, H. ve Oltulular, S. (2004). Türkiye’de Sanayileşme ve Ekonomik Büyüme Arasındaki Nedensellik Ilişkisi. Doğuş Üniversitesi Dergisi, 5 (2) $2004,219-226$

Thirwall, A. P. (2003). Growth and Development: With Special Reference to Developing Economies. Seventh Edition, Palgrave Macmillan, Hampshire.

Tüzüntürk, S. (2007). Panel Veri Modellerinin Tahmininde Parametre Heterojenliğinin Önemi: Geleneksel Phillips Eğrisi Üzerine Bir Uygulama. Atatürk Üniversitesi İktisadi ve İdari Bilimler Dergisi, 21(2), 1-14.

Uysal, D. (2007). Türkiye'de İstihdam, İssizlik ve Istihdam Politikaları, Türkiye Ekonomisi Makroekonomik Sorunlar ve Çözüm Önerileri. Çizgi Kitabevi, KONYA.

Ülgener, S. (1991). Milli Gelir, istihdam ve iktisadi Büyüme. Der yayınları, , ìstanbul.

Ünsal, E. (2007). iktisadi Büyüme. Ankara, İmaj Yayıncılık.

Yılmaz Göktaş, Ö. (2005). Türkiye Ekonomisinde Büyüme ile İ̧sizlik Oranları Arasındaki Nedensellik ilişsisi. Ekonometri ve İstatistik Dergisi, SAYI:2 İstanbul Ü. îktisat Fak. 2, 11-29. 